Check for updates

Cite this: RSC Adv., 2018, 8, 30374

Received 13th August 2018

Accepted 13th August 2018

DOI: $10.1039 / \mathrm{c} 8 \mathrm{ra06780e}$

rsc.li/rsc-advances

\title{
Silver-catalyzed direct benzylation of acetanilide: a highly efficient approach to unsymmetrical triarylmethanes $\uparrow$
}

\author{
Yuting Li, ${ }^{a}$ Yan Zhu, ${ }^{a}$ Guangliang Tu, ${ }^{a}$ Jingyu Zhang ${ }^{* b}$ and Yingsheng Zhao (D) *a
}

A highly efficient silver-catalyzed dibenzylation of acetanilides by employing the benzhydrol derivatives as the coupling partners to yield triphenylmethane derivatives has been developed. Various functional groups were tolerated, leading to the corresponding products in moderate to good yields. Preliminary experimental results indicated that the silver ions activate the arene rings and the strong acid $\mathrm{TfOH}$ provides the carbocations.

\section{Introduction}

Triarylmethane derivatives are a class of important substructures which can be usually found in organic dyes, ${ }^{1}$ fluorescent compounds, ${ }^{2}$ supramolecular structures, and pharmaceuticallyrelated compounds. ${ }^{3-5}$ In the last decade, several routes have been explored in the synthesis of the triarylmethane scaffold..$^{6,7}$ For example, the transition metal-catalyzed cross-coupling reaction has been developed to provide a direct approach to the synthesis of the triarylmethanes, which greatly enriched the synthetic methods to prepare these structures (Scheme 1a). ${ }^{8-14}$ However, the application of this method has been limited due to the requirement for the pre-functionalization during the synthesis of suitable coupling partners. Reduction of triarylmethanol derivatives offers another approach to obtain the triarylmethanes, which usually involved a multistep process (Scheme 1b). ${ }^{15,16}$ The Friedel-Crafts reaction is one of the most simple and widely employed routes for the preparation of triarylmethanes (Scheme 1c). ${ }^{17-20}$ The group of Mccubbin reported a pentafluorophenylboronic acid catalyzed method for the synthesis of triarylmethanes from benzhydrol with electronic rich arenes. ${ }^{21}$ Aoyama and co-workers developed a simple and efficient approach for alkylation of aromatics from alcohols with $\mathrm{NaHSO}_{4} / \mathrm{SiO}_{2} \mathrm{NaHSO}_{4} / \mathrm{SiO}_{2}$ as the catalyst. ${ }^{22}$ Nevertheless, this approach is limited by the substrate scope because electronic donating group-substituted arenes were required to realize the transformation. To the best of our knowledge, there

${ }^{a}$ Key Laboratory of Organic Synthesis of Jiangsu Province, College of Chemistry, Chemical Engineering and Materials Science, Soochow University, Suzhou 215123, China.E-mail: yszhao@suda.edu.cn

${ }^{b}$ College of Physics, Optoelectronics and Energy \& Collaborative Innovation Center of Suzhou Nano Science and Technology, Soochow University, Suzhou 215006, P. R. China.E-mail: jyzhang@suda.edu.cn

$\dagger$ Electronic supplementary information (ESI) available: CCDC 1842259-1842262. For ESI and crystallographic data in CIF or other electronic format see DOI: 10.1039/c8ra06780e are still no examples of coupling of diphenylmethanol and acetanilide. ${ }^{23}$ In this perspective, the development of a new catalyst system to address the aforementioned limitation for Friedel-Crafts reactions is highly imperative to construct the triarylmethanes. Herein, we report a silver-catalyzed direct benzylation of acetanilides with benzhydrol derivatives as the coupling partners under mild conditions (Scheme 1d). A wide variety of functional groups are well tolerated, yielding the corresponding benzylated products in moderate to good yields. Preliminary experimental results showed that the silver ions activate the arene rings and trifluoromethanesulfonic acid (TfOH) provides the carbocations.

The skeleton of the aniline derivative was usually found in the triphenylmethane-based bioactive compounds, such as

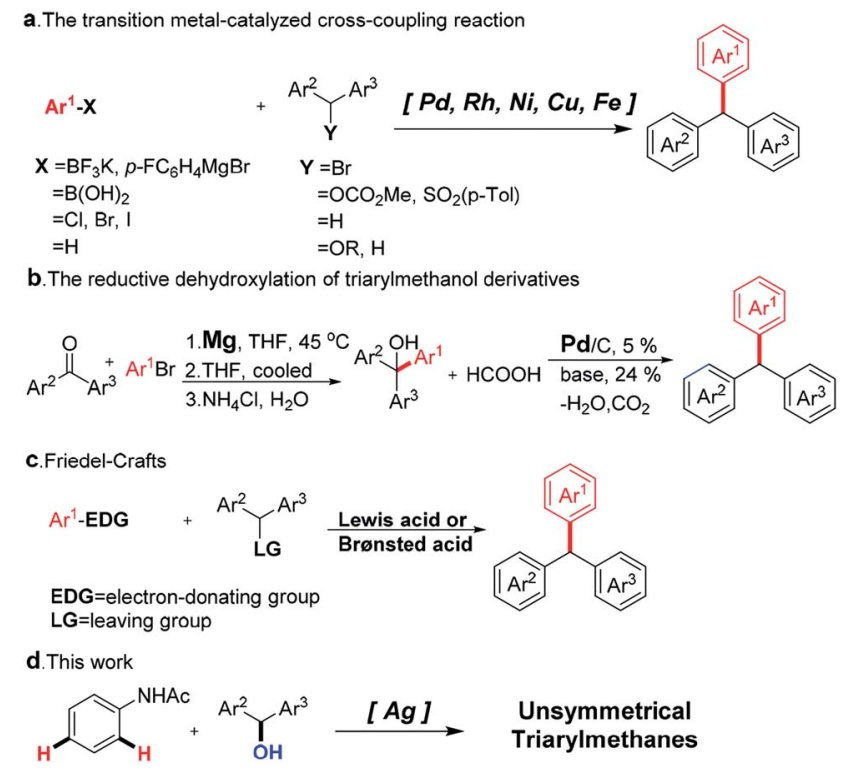

Scheme 1 Approaches to the synthesis of triphenylmethanes. 
pararosaniline, leucomalachite green, malachite green, and leucocrystal violet. ${ }^{1}$ Therefore, a highly efficient strategy for the construction the aniline-containing triphenylmethanes is highly desired.

\section{Results and discussion}

We envisioned that the aniline-containing triphenylmethane derivatives can be synthesized by treating the anilides with the benzhydrol derivatives via a transition metal catalyst. At the outset of our study, we treated acetanilide 1a with benzhydrol 2a in the presence of iron(III) chloride (20 mol\%) in dichloroethane at $120{ }^{\circ} \mathrm{C}$ to investigate whether the diphenyl-methanation could be performed. We were pleased to find that the diphenylmethylated product 3aa was generated in 5\% yield, along with the rest of the starting material 1a being recovered. Encouraged by this result, we next screened various Lewis acids such as $\mathrm{InBr}_{3}, \mathrm{Fe}(\mathrm{OTf})_{3}, \mathrm{Zn}(\mathrm{OTf})_{2}, \mathrm{Al}(\mathrm{OTf})_{3}, \mathrm{Sc}(\mathrm{OTf})_{3}$, and AgOTf to improve the efficiency of the reaction (Table 1). To our great delight, a dramatically improved yield $(76 \%)$ of 3aa was obtained when AgOTf was used as the catalyst. Next, we tried to decrease the catalyst loading to $5 \mathrm{~mol} \%$; the product 3aa was obtained in $60 \%$ yield. A satisfactory yield of 3aa could also be achieved with 10 mol\% AgOTf. In addition, several other solvents including toluene, $\mathrm{CH}_{3} \mathrm{CN}$, $t$-amyl-OH, and 1,4-dioxane were investigated, but none of them gave better yields than that of DCE. The control experiment showed that the catalyst is indispensable for this silver-promoted dibenzylation-reaction (see ESI $\dagger$ ).

With the optimized conditions in hand, we next explored the substrate scope to investigate the functional group tolerance of

Table 1 Optimization of reaction conditions ${ }^{a}$

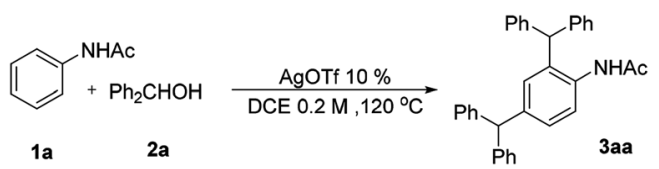

\begin{tabular}{llll}
\hline Entry & Catalyst & Solvent & Yield $(\%)^{b}$ \\
\hline 1 & $\mathrm{FeCl}_{3} 20 \%$ & DCE & 5 \\
2 & $\mathrm{InBr}_{3} 20 \%$ & DCE & Trace \\
3 & $\mathrm{Fe}(\mathrm{OTf})_{3} 20 \%$ & DCE & 64 \\
4 & $\mathrm{Zn}(\mathrm{OTf})_{2} 20 \%$ & DCE & 5 \\
5 & Al(OTf $)_{3} 20 \%$ & DCE & 0 \\
6 & Sc(OTf $)_{3} 20 \%$ & DCE & 0 \\
7 & AgOTf $20 \%$ & DCE & 76 \\
8 & AgOTf 10\% & DCE & 78 \\
9 & AgOTf $5 \%$ & DCE & 60 \\
10 & AgOTf $10 \%$ & Toluene & 6 \\
11 & AgOTf $10 \%$ & CH & 6 \\
12 & AgOTf $10 \%$ & $t$-Amyl-OH & 0 \\
13 & AgOTf $10 \%$ & 1,4-Dioxane & 5
\end{tabular}

${ }^{a}$ Reaction conditions: 1a $(0.1 \mathrm{mmol}), 2 \mathrm{a}(0.2 \mathrm{mmol})$, cat, solvent $(1 \mathrm{~mL})$, $120{ }^{\circ} \mathrm{C}, 8 \mathrm{~h} .{ }^{b}$ Yields were based on LC-MS analysis using acetyl benzene as an internal standard.

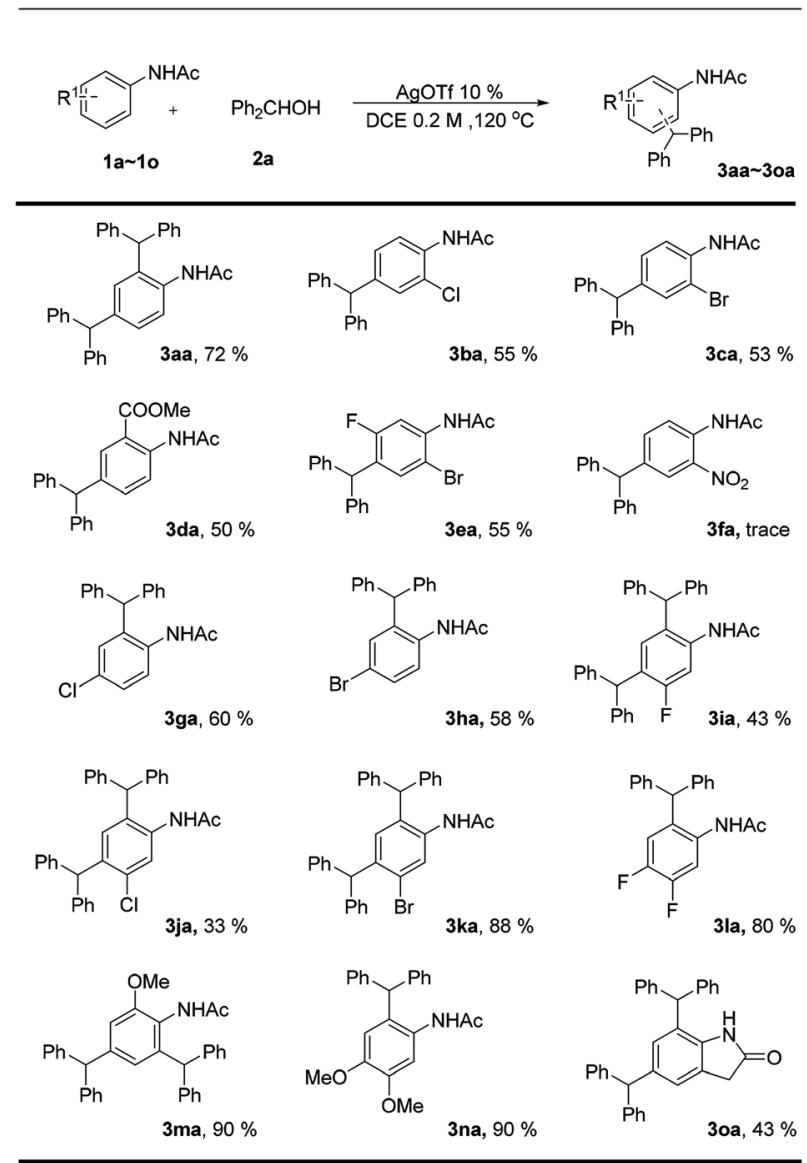

Scheme 2 Scope of acetanilide ${ }^{\mathrm{a}, \mathrm{b}}$. ${ }^{\mathrm{a}}$ Reaction conditions: 1a-1o $(0.1$ $\mathrm{mmol}), 2 \mathrm{a}(0.2 \mathrm{mmol}), \mathrm{AgOTf} 10 \%$, DCE $(1 \mathrm{~mL}), 120{ }^{\circ} \mathrm{C}, 8 \mathrm{~h}$. ' $Y$ ields of isolated products.

this silver trifluoromethanesulfonate-catalyzed dibenzylation reaction (Scheme 2). Initially, a series of ortho-substituted acetanilides (1b-1f) performed well under the standard conditions, which afforded the corresponding para-diphenylmethylated products in moderate yields. It is worth noting that all the ortho-substituted acetanilides with electron withdrawing groups yielded para-dibenzylated products, whereas those with electronic donating groups $(\mathbf{1 m}, \mathbf{1 0})$ afforded both the para- and ortho- position both diphenylmethylated products. This might be due to the fact that the electronic donating functional groups greatly activate the arene ring, which could trap the diphenylmethane carbon ion very quickly.

Next, we investigated the para-substituted acetanilides (19, 1h, and 1l); the ortho-diphenylmethylated products were obtained in good yields, which indicated that the electronic effects greatly affect the reactivity of the acetanilides. Interestingly, all the meta-substituted substrates provide both the ortho- and para-diphenylmethylated products (3ia-3ka) in good to moderate yields. The X-ray crystal structures of $3 \mathbf{c a}, 3 \mathbf{h a}, 3 \mathbf{j b}$, and 3la are shown in Fig. 1.

The bromide substituted arenes can be further transformed into various other functional groups by well-known crosscoupling reactions. ${ }^{24}$ Therefore, 2-bromoacetanilide was 

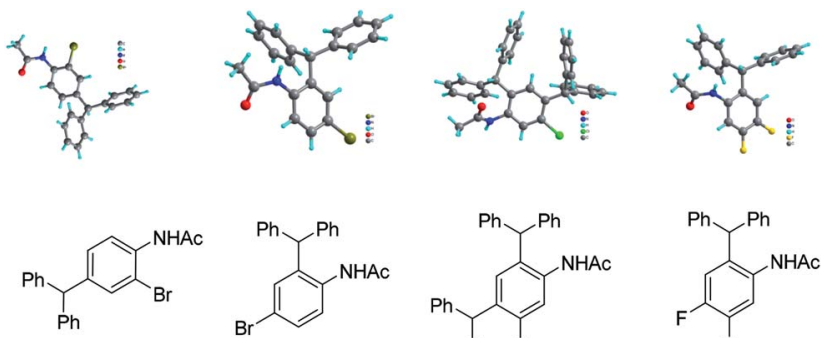

3ca

3ha

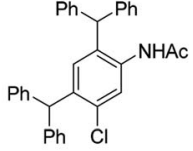

$3 j a$

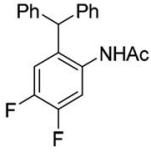

3la

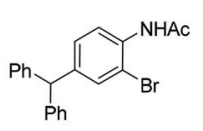

Fig. 1 X-ray crystal structures of 3ca, 3ha, 3jb and 3 la
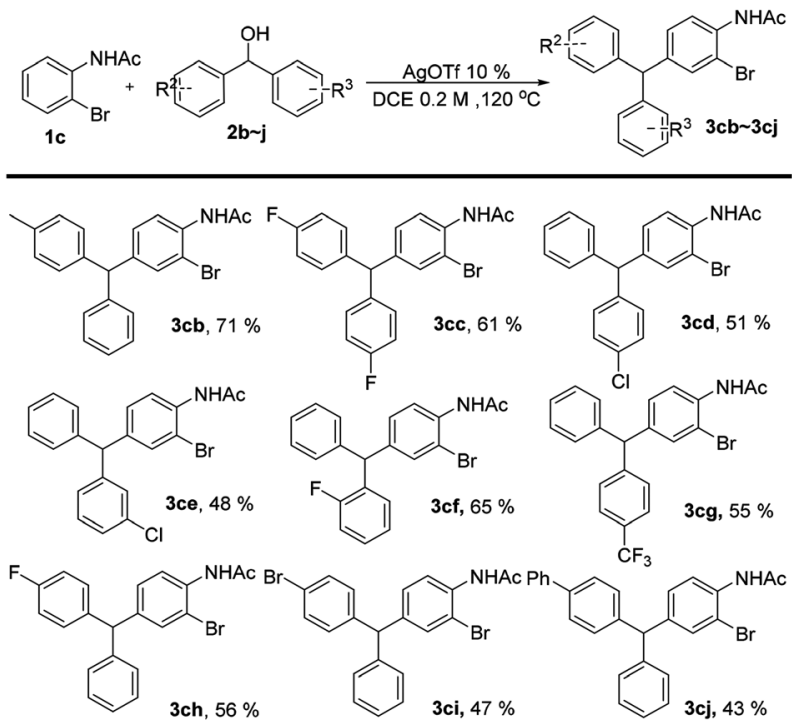

Scheme 3 Scope of benzhydrol ${ }^{a, b}$. ${ }^{a}$ Reaction conditions: 1c $(0.1$ $\mathrm{mmol}), 2 \mathrm{~b}-2 \mathrm{j}(0.2 \mathrm{mmol}), \mathrm{AgOTf} 10 \%$, DCE $(1 \mathrm{~mL}), 120{ }^{\circ} \mathrm{C}, 8 \mathrm{~h} .{ }^{\mathrm{b}}$ Yields of isolated products.

employed to investigate the scope of benzhydrol and the results were listed in Scheme 3. The results clearly show that the functional groups, such as $\mathrm{Me}, \mathrm{F}, \mathrm{Cl}, \mathrm{Br}, \mathrm{CF}_{3}$, and $\mathrm{Ph}$ were all fully tolerated in this reaction. All the dibenzylation took place selectively at the para-position. Even though the exact reason is unclear, we speculated that the steric effect is the major reason for the para-selectivity.

To further demonstrate the synthetic utility of the developed synthetic protocol, gram-scale reactions were performed. To our

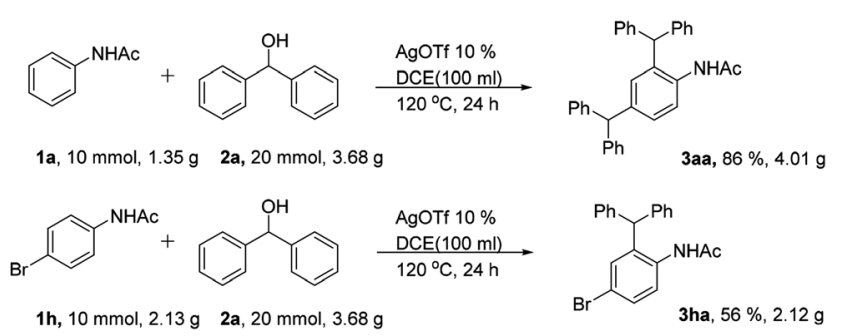

Scheme 4 Gram-scale reactions. delight, all the scale up reactions provided the corresponding products (3aa, 3ha) in good yields (Scheme 4).

In order to propose the reaction mechanism of this silvercatalyzed selective dibenzylation reaction, several experiments were further performed. TfOH was used instead of AgOTf, which afforded 35\% 3aa (Scheme 5a); this result indicated that silver has a significant role in the realization of the dibenzylation reaction. However, when silver acetate was used as the catalyst, no dibenzylated product was obtained and the starting material 1a was completely recovered (Scheme 5b). Interestingly, when silver acetate $(10 \mathrm{~mol} \%)$ and $\mathrm{TfOH}(10 \mathrm{~mol} \%)$ were used to instead of AgOTf, a good yield of 3aa was achieved (Scheme $5 \mathrm{c}$ ). Moreover, when we added a proton scavenger $\mathrm{Et}_{3} \mathrm{~N}(10 \mathrm{~mol} \%)$ to the reaction, the reaction was well inhibited (scheme $5 \mathrm{~d}$ ). This result might indicate that the $\mathrm{TfOH}$ would generate the diphenyl-methane carbocation (complex II), and the silver ions might coordinate with oxygen to activate the acetanilides (complex I). To further support this point, $N$-methylacetanilide was subjected to the standard reaction conditions to investigate the occurrence of dibenzylation (Scheme 5e). Impressively, there was no dibenzylated product and only the starting material was recovered, which further validated our proposal. Next, the deuteration experiment was performed by directly adding $\mathrm{D}_{2} \mathrm{O}$ into the reaction (Scheme $5 \mathrm{f}$ ). The result from this experiment may indicate that the silver only acted as a Lewis acid in this reaction.

Based on these results and previous reports ${ }^{6,7}$ a plausible reaction mechanism was proposed in Scheme 6 . The

a

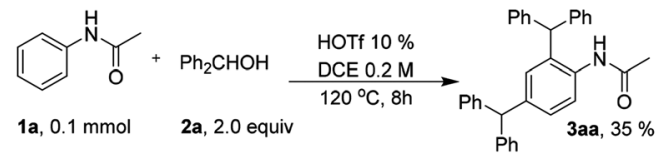

b

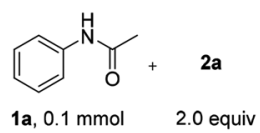

c
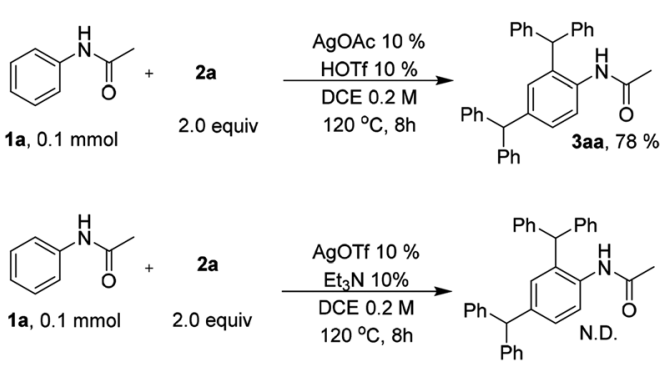

e
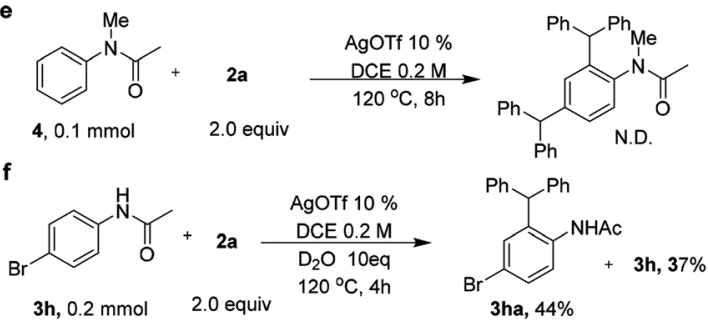

Scheme 5 Preliminary mechanistic study. 


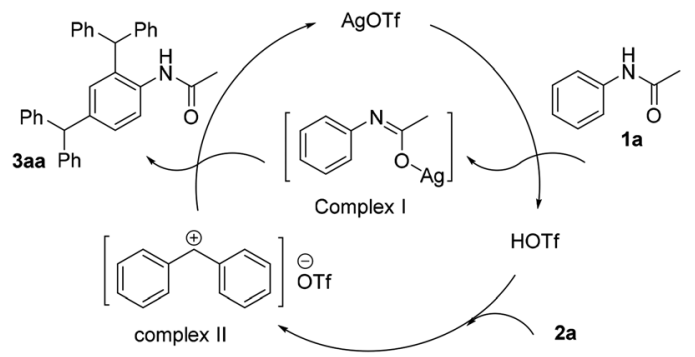

Scheme 6 Proposed reaction mechanism.

carbocation I might be formed by combination with silver ions under acidic conditions. Meanwhile, the strong Lewis acid TfOH would enable the formation of the carbocation (complex II), which was further trapped by the complex I, affording the dibenzylated product.

\section{Conclusions}

In conclusion, we have developed a highly efficient approach for the synthesis of triphenylmethane derivatives through the direct combination of acetanilides and diphenylmethanol derivatives using AgOTf as the catalyst. A wide variety of functional groups are well tolerated, leading to the corresponding benzylated products in moderate to good yields. Preliminary experimental results indicated that the silver ions activate the arene rings and $\mathrm{TfOH}$ provides the carbocations. Further applications and mechanistic studies are now underway in our lab.

\section{Conflicts of interest}

There are no conflicts to declare.

\section{Acknowledgements}

We gratefully acknowledge financial support from the Natural Science Foundation of China (Nos. 21772139 and 21572149). Project of Scientific and Technologic Infrastructure of Suzhou (SZS201708) and the PAPD Project are also gratefully acknowledged.

\section{Notes and references}

1 Reviews: (a) D. F. Duxbury, Chem. Rev., 1993, 93, 381-433; (b) M. S. Shchepinov and V. A. Korshun, Chem. Soc. Rev., 2003, 32, 170-180; (c) V. Nair, S. Thomas, S. C. Mathew and K. G. Abhilash, Tetrahedron, 2006, 62, 6731-6747.

2 (a) C. D. Mason and F. F. Nord, J. Org. Chem., 1951, 16, 722727; (b) V. V. Ghaisas, B. J. Kane and F. F. Nord, J. Org. Chem., 1958, 23, 560-565; (c) M. Irie, J. Am. Chem. Soc., 1983, 105, 2078-2079; (d) R. Muthyala, A. R. Katritzky and X. F. Lan, Dyes Pigm., 1994, 25, 303-324.

3 (a) R. A. Al-Qawasmeh, Y. Lee, M. Y. Cao, X. Gu, A. Vassilakos, J. A. Wright and A. Young, Bioorg. Med. Chem., 2004, 14, 347350; (b) G. Panda, J. K. Mishra, V. Chaturvedi,
A. K. Srivastave, R. Srivastava and B. S. Srivastava, Bioorg. Med. Chem., 2004, 12, 5269-5276.

4 (a) R. S. Dothager, K. S. Putt, B. J. Allen, B. J. Leslie, V. Nesterenko and P. J. Hergenrother, J. Am. Chem. Soc., 2005, 127, 8686-8696; (b) Shagufta, A. K. Srivastava, R. Sharma, R. Mishra, A. K. Balapure, P. S. R. Murthy and G. Panda, Bioorg. Med. Chem., 2006, 14, 1497-1505.

5 (a) M. K. Parai, G. Panda, V. Chaturvedi, Y. K. Manju and S. Sinha, Bioorg. Med. Chem. Lett., 2008, 18, 289-292; (b) P. R. alchaudhuri, V. Nesterenko and P. J. Hergenrother, J. Am. Chem. Soc., 2008, 130, 10274-10281.

6 Reviews: (a) M. Shiri, M. A. Zolfigol, H. G. Kruger and Z. Tanbakouchian, Chem. Rev., 2010, 110, 2250-2293; (b) M. Nambo and C. M. Crudden, ACS Catal., 2015, 5, 47344742 .

7 (a) M. Barbero, S. Cadamuro, S. Dughera, C. Magistris and P. Venturello, Org. Biomol. Chem., 2011, 9, 8393-8399; (b) F. L. Sun, X. J. Zheng, Q. Gu, Q. L. He and S. L. You, Eur. J. Org. Chem., 2010, 47-50; (c) S. Dhiman and S. S. V. Ramasastry, Org. Biomol. Chem., 2013, 11, 80308035; (d) P. Arde and R. V. Anand, RSC Adv., 2016, 6, 77111-77115.

8 (a) G. A. Molander and M. D. Elia, J. Org. Chem., 2006, 71, 9198-9202; (b) A. López-Pérez, J. Adrio and J. C. Carretero, Org. Lett., 2009, 11, 5514-5517.

9 J. Y. Yu and R. Kuwano, Org. Lett., 2008, 10, 973-976.

10 (a) L. L. Cao, X. N. Li, F. Y. Meng and G. F. Jiang, Tetrahedron Lett., 2012, 53, 3873-3875; (b) T. Niwa, H. Yorimitsu and K. Oshima, Org. Lett., 2007, 9, 2373-2375; (c) G. Song, Y. Su, X. Gong, K. Han and X. Li, Org. Lett., 2011, 13, 19681971; (d) S. Tabuchi, K. Hirano, T. Satoh and M. Miura, J. Org. Chem., 2014, 79, 5401-5411.

11 X. Zhao, G. Wu, Y. Zhang and J. Wang, J. Am. Chem. Soc., 2011, 133, 3296-3299.

12 J. Zhang, A. Bellomo, A. D. Creamer, S. D. Dreher and P. J. Walsh, J. Am. Chem. Soc., 2012, 134, 13765-13772.

13 M. Tobisu, A. Yasutome, H. Kinuta, K. Nakamura and N. Chatani, Org. Lett., 2014, 16, 5572-5575.

14 (a) B. F. Shi, N. Maugel, Y. H. Zhang and J. Q. Yu, Angew. Chem., Int. Ed., 2008, 47, 4882-4886; (b) X. Shen, N. N. Gu, Y. Liu and B. Dai, Chin. J. Chem., 2016, 34, 1033-1038.

15 G. Cravotto, A. Procopio, M. Oliverio, L. Orioa and D. Carnaroglioa, Green Chem., 2011, 13, 2806-2809.

16 S. Sawadjoon, A. Lundstedt and J. S. M. Samec, ACS Catal., 2013, 3, 635-642.

17 (a) J. Esquivias, R. G. Arrayas and J. C. Carretero, Angew. Chem., Int. Ed., 2006, 45, 629; (b) V. Nair, N. Vidya and K. G. Abhilash, Synthesis, 2006, 3647.

18 (a) S. H. Lin and X. Y. Lu, J. Org. Chem., 2007, 72, 9757; (b) S. Podder, J. Choudhury, U. K. Roy and S. Roy, J. Org. Chem., 2007, 72, 3100.

19 (a) I. Alonso, J. Esquivias, R. G. Arrayas and J. C. Carretero, J. Org. Chem., 2008, 73, 6401; (b) G. J. Li, E. J. Wang, Y. Chen, Y. H. Liu and P. G. Wang, Tetrahedron, 2008, 64, 9033; (c) C. R. Liu, M. B. Li, C. F. Yang and S. K. Tian, Chem. Commun., 2008, 1249. 
20 S. Gao, X. Xu, H. Yao and A. J. Lin, Eur. J. Org. Chem., 2016, 3006-3012.

21 J. A. McCubbin and O. V. Krokhin, Tetrahedron Lett., 2010, 51, 2447-2449.

22 Y. Sato, T. Aoyama, T. Takido and M. Kodomari, Tetrahedron, 2012, 68, 7077-7081.

23 (a) R. Sanz, A. Martínez, D. Miguel, J. M. Álvarez-Gutiérrez and F. Rodríguez, Adv. Synth. Catal., 2006, 348, 1841-1845; (b) J. L. Bras and J. Muzart, Tetrahedron, 2007, 63, 79427948; (c) H. B. Sun, B. Li, S. Chen, J. Li and R. Hua, Tetrahedron, 2007, 63, 10185-10188; (d) J. A. McCubbin and O. V. Krokhin, Tetrahedron Lett., 2010, 51, 2447-2449; (e) J. A. McCubbin and O. V. Krokhin, Tetrahedron Lett., 2010, 51, 2447-2449.
24 Reviews: (a) N. Miyaura and A. Suzuki, Chem. Rev., 1995, 95, 2457-2483; (b) C. Liu, H. Zhang, W. Shi and A. Lei, Chem. Rev., 2011, 111, 1780-1824; (c) J. Pouliot, F. Grenier, J. T. Blaskovits, S. Beaupré and M. Leclerc, Chem. Rev., 2016, 116, 14225-14274; (d) P. R. Castillo and S. L. Buchwald, Chem. Rev., 2016, 116, 12564-12649; (e) H. Yi, G. Zhang, H. Wang, Z. Huang, J. Wang, A. K. Singh and A. W. Lei, Chem. Rev., 2017, 117, 9016-9085; (f) R. J. Procter, J. J. Dunsford, P. J. Rushworth, D. G. Hulcoop, R. A. Layfield and M. J. Ingleson, Chem.Eur. J., 2017, 23, 15889-15893; (g) Y. Xia, D. Qiu and J. B. Wang, Chem. Rev., 2017, 117, 13810-13889; (h) T. Komiyama, Y. Minami, Y. Furuya and T. Hiyama, Angew. Chem., Int. Ed., 2018, 57, 1987-1990. 